\title{
Encyclopedia
}

\section{Job quality}

Created by: Nádia Simões

Version received: 14 November 2019

check for

updates

We present the concept of job quality and its measurement. We discuss a recently introduced approach which evaluates job quality at the worker-level (micro-level). It considers eleven dimensions grouped into three main groups: core objective dimensions, complementary objective dimensions, and subjective dimensions.

In recent years, the measurement of job quality has received significant attention in specialized literature. In what specifically concerns the development of job quality measures, the importance of this topic on the European agenda and on the agenda of international organizations such as the ILO or the OECD was critical.

At the micro-level, "the indicators are based on a concept of job quality that is more worker-related, being constructed from a survey focused on the characteristics of the job and on the quality of the match between worker and job" [프.

In this context, the central question is: what are the critical dimensions of job quality? There are, of course, alternative proposals. Here, we briefly describe the measure advanced by Simoes et al. ${ }^{[\underline{1}]}$. In that study which aims to evaluate the level and the determinants of job quality in Europe - eleven dimensions are considered. These dimensions are grouped into three categories as follows:

\section{Core Objective Dimensions}

- Pay (average net monthly income);

- Physical working conditions (evaluating if the worker is exposed to noise, high/low temperatures, chemical products, tobacco smoke, etc., and if the job involve tiring or painful positions, repetitive movements, etc.);

- Intensity (evaluating if the job involves working at very high speed and/or with tight deadlines);

- Autonomy (concerning the order of tasks or the methods of work);

- Job Security.

\section{Complementary Objective Dimensions}

- Health (analyzing if the work affects health);

- Promotion prospects.

\section{Subjective Dimensions}

- Work-life balance;

- Interpersonal relations;

- Intrinsic rewards (evaluating if the individual feels that he/she is doing a useful work).

Based on these eleven dimensions, it is possible to build a job quality composite index, which is obtained as the weighted average of the scores reached in each individual dimension. To that end it is necessary to define the weights to be given to the different dimensions. There is evidence in the literature supporting 
the idea that some dimensions are more relevant than others when workers evaluate the quality of their jobs. For example, Rose ${ }^{[\underline{2}]}$ and $\mathrm{Clark}^{[\underline{3}]}$ found that pay, job security, and interesting job were the dimensions most frequently indicated as the most critical ones. Taking this evidence as support, Simoes et al. ${ }^{[1]}$ create the composite index of job quality giving weight 2 to these dimensions and weight 1 to all the remaining ones. The job quality index ranges between 0 (minimum level of job quality) and 1 (maximum level of job quality).

\section{References}

1. Nádia Simões; Nuno Crespo; José Castro Pinto; Determinants of job quality - Evidence for European country groups*. Acta Oeconomica 2015, 65, 299-323, 10.1556/032.65.2015.2.6.

2. Michael Rose; Good Deal, Bad Deal? Job Satisfaction in Occupations. Work, Employment and Society 2003, 17, 503530, 10.1177/09500170030173006.

3. Andrew E. Clark; Your Money or Your Life: Changing Job Quality in OECD Countries.British Journal of Industrial Relations 2005, 43, 377-400, 10.1111/j.1467-8543.2005.00361.x.

\section{Keywords}

job quality; job satisfaction; occupations; work

(c) 2019 by the author(s). Distribute under a Creative Commans CC BY license 